\title{
EFFECTS OF MELATONIN AND LUZINDOLE ON PLASMA LEVELS OF TISSUE FACTOR, TISSUE FACTOR PATHWAY INHIBITOR AND VON WILLEBRAND FACTOR IN RATS
}

\author{
Negrin Negrev ${ }^{1}$, Yuri Nyagolov ${ }^{2}$, Antoaneta Zarkova ${ }^{3}$, Irina Pashalieva ${ }^{1}$, \\ Emiliya Stancheva ${ }^{1}$, Diana Radkova ${ }^{4}$ \\ ${ }^{1}$ Department of Physiology and Pathophysiology, Medical University of Varna, Bulgaria, \\ ${ }^{2}$ Department of Physiology, Medical University of Sofia, Bulgaria \\ ${ }^{3}$ Specialized Hospital for Active Treatment of Hematological Diseases, Sofia, Bulgaria \\ ${ }^{4}$ Department of Infectious Diseases, Medical University of Varna, Bulgaria
}

\section{ABSTRACT}

INTRODUCTION: The role of melatonin in hemostasis is still poorly studied.

PURPOSE: The purpose of this study was to investigate the effects of melatonin and luzindole, inhibitor of the melatonin receptors $-\mathrm{MT}_{1}$ and $\mathrm{MT}_{2}$, on plasma levels of tissue factor, tissue factor pathway inhibitor and von Willebrand factor.

MATERIAL AND METHODS: The study was performed on 52 male Wistar rats, kept at 12/12 h natural regimen dark/light. The daily doses of melatonin $0.2 \mathrm{mg} / \mathrm{kg} \mathrm{b.m.} \mathrm{and} \mathrm{luzindole} 0.4 \mathrm{mg} / \mathrm{kg} \mathrm{b.m}$. were applied subcutaneously twice daily at intervals of $12 \mathrm{~h}$ for three consecutive days. The rats were distributed into four equal groups $(n=13)$ and were treated as follows: the first group (control group) - by saline; the second group - by melatonin; the third group - by luzindole; and the fourth group - by luzindole and an hour later by melatonin.

RESULTS: The results show that melatonin significantly increases the plasma levels of TF, reduces the values of free TFPI antigen and free TFPI activity, and increases the values of vWF antigen and vWF activity. Applied alone, luzindole lowers the plasma levels of TF, increases the values of free TFPI antigen and free TFPI activity; decreases the values of vWF antigen and vWF activity. Pretreatment with luzindole repeats the effect of self-administration. The received data show that melatonin induces a pronounced tendency to hypercoagulability in rats by a significant increase in TF, a decrease of free TFPI and free TFPI activity, as well as an increase in vWF antigen and vWF activity.

CONCLUSIONS: Lizindole self-administration and pretreatment show a decisive involvement of $\mathrm{MT}_{1}$ and $\mathrm{MT}_{2}$ receptors for accomplishing the effects of the hormone.

Keywords: melatonin, luzindole, TF, TFPI, $v W F, M T_{1}$ and $M T_{2}$ receptors, hypercoagulability

Address for correspondence:

Negrin N. Negrev

55 "Marin Drinov" Street,

Medical University - Varna,

9002 Varna, Bulgaria

e-mail:negrev@mu-varna.bg

Received: January 22, 2014

Accepted: March 11, 2015

\section{INTRODUCTION}

Tissue factor (TF), also known as plasma factor III, is a transmembrane glycoprotein which plays an initiating role for blood coagulation in the extrinsic pathway $(1,2)$. It is widely present in all tissues but is expressed mostly in subendothelial cells, adventitial fibroblasts, alveolar cells, cardiomyocytes, astrocytes, trophoblasts, and others $(3,4,5)$. The tissue fac- 
Negrin Negrev, Yuri Nyagolov, Antoaneta Zarkova et al.

tor has a high affinity to the VIIa factor and together they form the TF/FVIIa complex (tenase complex), which activates IX and X factors, and thus, the coagulation cascade to form fibrin $(6,7)$.

The tissue factor pathway inhibitor (TFPI) is a major physiological regulator of the TF-induced coagulation $(8,9)$. Its biosynthesis is associated primarily with the microvascular endothelium $(10,11)$. The TFPI molecule contains three consecutive Kunitztype protease inhibitor domains, and the second domain (K2) connects and inhibits the Xa factor, and the first (K1) - with the tenase complex (TF/FVIIa) $(12,13)$. As a result of this, a quaternary complex TFPI - TF/FVIIa - FXa is formed, which is inactive (14). This complex is the basis of the regulatory effect of TFPI on the initiated by the TF intrinsic pathway for thrombin generation $(1,15)$.

The Von Willebrand factor (vWF) is a glycoprotein, which performs two key functions in normal hemostasis. The first - mediates the adhesion of platelets to the subendothelial matrix after vascular injury $(16,17)$ and the second - protects the VIII factor from proteolytic degradation (18). vWF is released into circulation by secretion from endothelial cells (accumulates in Weibel-Palade bodies) and platelets (their alpha granules) $(19,20)$. It is well known that abnormalities in platelet plug and fibrin formation are observed in patients with von Willebrand disease (17).

\section{PURPOSE}

The purpose of this study was to investigate the effect of melatonin and luzindole (melatonin receptors inhibitor - type 1 and 2) on plasma levels of tissue factor, tissue factor pathway inhibitor and von Willebrand factor.

\section{MATERIAL AND METHODS}

Experiments were carried out on 52 white male Wistar rats, weighing 200-220 g, kept at natural regimen dark/light 12/12 h in accordance with European Convention and Directives (Protection of animals used for experimental purposes, Council Directive 86/609/EEc of November 1986, Directive 2010/63/ EU of the European Parliament and of the Council of September 2010). Rats were fed by standard food and water ad libitum. The daily doses of melatonin (Merck, Germany) $0.2 \mathrm{mg} / \mathrm{kg}$ b.m., and luzindole (Sigma Chemicals, USA) $-0.4 \mathrm{mg} / \mathrm{kg}$ b.m. were ap- plied s.c. twice daily at intervals of $12 \mathrm{~h}$, for three consecutive days. The upper doses were determined experimentally in preliminary studies and according to literature data. The rats were distributed into four equal groups $(n=13)$ and were treated as follows: the first group (C) (control group) - by saline; the second group - by melatonin (M); the third group - by luzindole (L); and the fourth group - by luzindole and an hour later by melatonin $(\mathrm{L}+\mathrm{M})$.

The necessary blood volume from a rat was received by cardiac puncture under urethane narcosis in single usage plastic tubes, using sodium citrate $0.11 \mathrm{~mol} / 1$ (blood citrate ratio 9:1) as anticoagulant.

TF was determined by an American Diagnostica, inc. test (USA), and by performing Diagnostica Stago tests (France), the following were determined: free TFPI, free TFPI activity, vWF antigen (vWF:Ag) and vWF activity, defined by collagen binding capacity (vWF:CB capacity).

Rats were autopsied and examined for macroscopic haemorrhages. Preparations from internal organs were stained by hematoxylin-eosin and for fibrin by Weigert, and inspected for microhaemorrhages and intravascular coagulation.

\section{STATISTICAL ANALYSIS}

Data were processed by variation analysis using Student-Fisher's t-test on GrafpadPRYSM 4.2 software. Values of $\mathrm{p}<0.05$ were considered significant.

\section{RESULTS}

Results are presented in Fig. 1-5. Fig. 1 shows that melatonin increases plasma levels of TF $(\mathrm{pg} / \mathrm{ml})$ from $120.30 \pm 6.29$ to $159.80 \pm 10.42$, $(\mathrm{p}<0.01)$. Luzindole self-administration and luzindole pretreatment with a subsequent injection of melatonin, decreases the values of TF to $42.23 \pm 3.05(\mathrm{p}<0.001)$ and $52.31 \pm 6.340(\mathrm{p}<0.001)$, respectively. Changes in plasma levels of free TFPI (ng/ml) (Fig. 2), indicate that melatonin decreases its values from $11.87 \pm 0.54$ in the control group - to $5.50 \pm 0.46(\mathrm{p}<0.001)$, luzindole increases them to $15.48 \pm 1.06(\mathrm{p}<0.01)$, while pretreatment with luzindole - to $16.03 \pm 0.85$ ( $\mathrm{p}<0.001)$.

Melatonin reduces the free TFPI activity (Fig. 3) from $93.41 \pm 6.96$ in controls - to $53.19 \pm 9.29(\mathrm{p}<0.01)$, luzindole increases it to $146.50 \pm 11.05(\mathrm{p}<0.001)$, as does the pretreatment with luzindole - to $153.40 \pm 9.31$ $(\mathrm{p}<0.001)$. 




Fig. 1. Effects of melatonin $(0.2 \mathrm{mg} / \mathrm{kg}$ b.w.) and luzindole $(0.4 \mathrm{mg} / \mathrm{kg}$ b.w.), applied s.c. to male Wistar twice daily at intervals of $12 \mathrm{~h}$, for three consecutive days on TF level (pg/ml). TF - Tissue factor; $C$ - control group, injected by saline; $M$ - melatonin; $L$ - luzindol; $L+M-l$ luzindol followed after $1 \mathrm{~h}$ by melatonin

$$
{ }^{* * *} p<0.001 ;{ }^{* *} p<0.01
$$

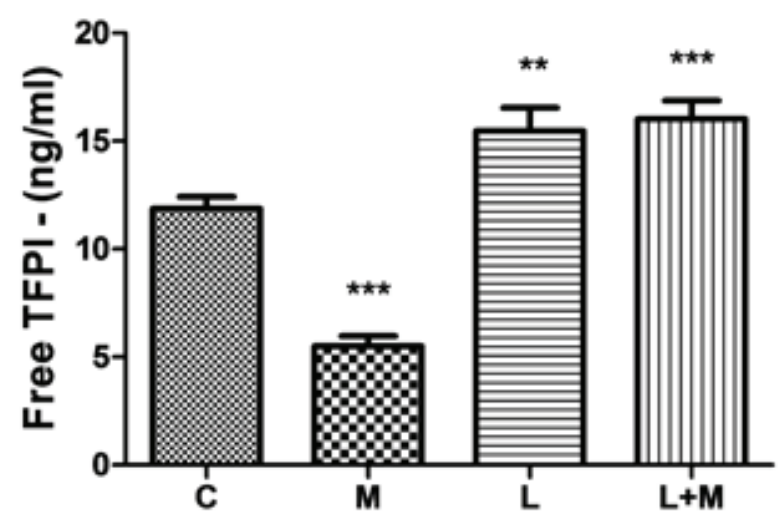

Fig. 2. Effects of melatonin $(0.2 \mathrm{mg} / \mathrm{kg} \mathrm{b.w.)}$ and luzindole $(0.4 \mathrm{mg} / \mathrm{kg}$ b.w.), applied s.c. to male Wistar twice daily at intervals of $12 \mathrm{~h}$, for three consecutive days on free TFPI $(\mathrm{ng} / \mathrm{ml})$. Free TFPI - free Tissue factor pathway inhibitor; $C$ - control group, injected by saline; $M$ - melatonin; $L$ luzindol; $L+M$ - luzindol followed after $1 \mathrm{~h}$ by melatonin

$$
{ }^{* * *} p<0.001 ;{ }^{* *} p<0.01
$$

Plasma levels of vWF antigen (Fig. 4) under the influence of melatonin are highly elevated $(122.50 \pm 6.63, \mathrm{p}<0.001)$ compared to the control group rats $(82.01 \pm 6.42)$. Treatment with luzindole was followed by a reduction of vWF antigen levels to $49.01 \pm 4.05$ ( $\mathrm{p}<0.001)$. Strong reduction was also observed after pretreatment with luzindole $(41.10 \pm 3.41$, $\mathrm{p}<0.001)$.

The vWF activity increases under the influence of melatonin to $167.70 \pm 9.65(\mathrm{p}<0.01)$ (Fig. 5), rela-

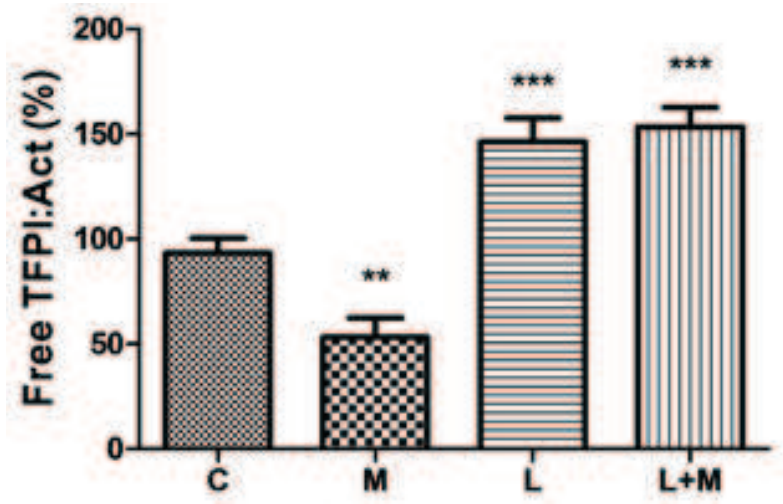

Fig. 3. Effects of melatonin $(0.2 \mathrm{mg} / \mathrm{kg} \mathrm{b.w.)}$ and luzindole $(0.4 \mathrm{mg} / \mathrm{kg}$ b.w.), applied s.c. to male Wistar twice daily at intervals of $12 \mathrm{~h}$, for three consecutive days on activity free TFPI (\%). Free TFPI:Act - free Tissue factor pathway inhibitor activity; $C$ - control group, injected by saline; $M$ - melatonin; L - luzindol; $L+M$ - luzindol followed after $1 \mathrm{~h}$ by melatonin

$$
{ }^{* * *} p<0.001 ;{ }^{* *} p<0.01
$$

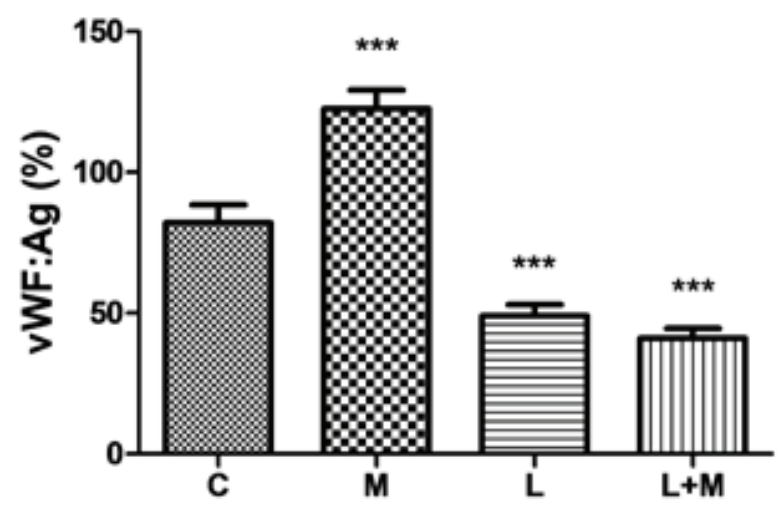

Fig. 4. Effects of melatonin $(0.2 \mathrm{mg} / \mathrm{kg} \mathrm{b.w.)}$ and luzindole (0.4 mg/kg b.w.), applied s.c. to male Wistar twice daily at intervals of $12 \mathrm{~h}$, for three consecutive days on VWF antigen (\%). VWF:Ag - von Willebrand factor, antigen; $C$ - control group, injected by saline; $M$ - melatonin; $L$ luzindol; $L+M-$ luzindol followed after $1 \mathrm{~h}$ by melatonin

$$
{ }^{* * *} p<0.001
$$

tive to controls $(127.10 \pm 5.79)$. Luzindole reduces the activity to $68.91 \pm 5.15(\mathrm{p}<0.001)$, while pretreatment with luzindol - down to $60.54 \pm 3.04(\mathrm{p}<0.001)$.

\section{DISCUSSION}

Fig. 1 shows that melatonin, administered to the rats, causes a significant increase in plasma levels of $\mathrm{TF}(\mathrm{p}<0.01)$ compared to the control group. Since TF is known primarily as a trigger of the extrinsic coagulation pathway and thrombogenesis in a 
Negrin Negrev, Yuri Nyagolov, Antoaneta Zarkova et al.



Fig. 5. Effects of melatonin $(0.2 \mathrm{mg} / \mathrm{kg} \mathrm{b.w.)}$ and luzindole (0.4 mg/kg b.w.), applied s.c. to male Wistar twice daily at intervals of $12 \mathrm{~h}$, for three consecutive days on activity $v W F: C B$ (\%). $v W F: C B$ capacity - activity $v W F$ as estimated by collagen binding capacity; $C$ - control group, injected by saline; $M$ - melatonin; $L$ - luzindol; $L+M-$ luzindol followed after $1 \mathrm{~h}$ by melatonin

$$
{ }^{* * *} p<0.001 ;{ }^{* *} p<0.01
$$

number of diseases $(1,2,21)$, it could be assumed that melatonin induces a tendency to hypercoagulability. This assumption is supported by our previous study (22) where it was shown that this hormone violates the equilibrium between the coagulant and anticoagulant system in favor of the coagulant. The foregoing analysis allows to assume that increased plasma levels of TF under the influence of melatonin are a part of the mechanism explaining the tendency to hypercoagulability, which is convincingly shown in the already published article. Self-administration of luzindole strongly reduces the TF levels, $(p<0.001)$, which gives grounds most likely to assume that blocking the melatonin receptors $\left(\mathrm{MT}_{1}\right.$ and $\mathrm{MT}_{2}$ ) removes to a large extent the effect of endogenous melatonin on structures associated with the formation of this factor. We cannot exclude the fact, albeit hypothetically, that luzindole may inhibit somewhat the biosynthesis and secretion of endogenous melatonin, which is relevant to the final effect. For now, there are no published data on the level of melatonin in plasma after administration of luzindole. Of particular interest are the results from the fourth group of animals, where melatonin is administered after pretreatment with luzindole. On the one hand, the results repeate those from the third group (luzindole only). On the other hand, it shows that blocking the melatonin receptors suppresses the effect of endoge- nous and exogenous melatonin, i.e. these results are new evidence for the role of melatonin receptors as well as the importance of endogenous melatonin in TF formation.

The results presented in Fig. 2 and Fig. 3 are a logical continuation of those in Fig. 1, showing the changes in TFPI, also known as major physiological inhibitor of TF-mediated coagulation cascade $(1,8,9)$. Based on this fact and the well-known mechanism of TFPI action (12-15) there is reason to assume that the significantly lower levels of free TFPI (Fig. 2) $(\mathrm{p}<0.001)$ and especially free TFPI activity (Fig. 3) $(\mathrm{p}<0.01)$ under the influence of melatonin, are inevitably accompanied by development of a tendency to hypercoagulability. Applied alone, luzindole increases significantly free TFPI (Fig. 2) (p<0.01), as well as its activity (Fig. 3) ( $\mathrm{p}<0.001)$. This fact shows that melatonin receptors ( $\mathrm{MT}_{1}$ and $\mathrm{MT}_{2}$ ) have multidirectional effects. On the one hand, they mediate the effects of melatonin, and on the other - their blocking activates the formation of both the free form TFPI, and free TFPI with high activity. Our study does not allow to conclude whether blocking of these receptors initiates increased biosynthesis of TFPI, or changes only in the surveyed indicators - free TFPI and free TFPI activity. Pretreatment with luzindole almost entirely repeats the results from the third group (luzindole only) and is a new evidence that the effects of exogenous and endogenous melatonin are blocked, and also for the significance of its receptors on the plasma level of free TFPI and its activity.

The presented in Fig. 4 and Fig. 5 results show the effects of melatonin and luzindole on vWF, defined as antigen and activity. The interpretation of these results would have been accurate in the light of the literature data which show that vWF, on the one hand, has a role in triggering normal hemostasis, and the other - the increase of its plasma level is to be regarded as a risk thrombogenic factor $(16,23)$. Therefore, the significantly elevated vWF antigen level (Fig. 4) $(\mathrm{p}<0.001)$ and its activity (Fig. 5) $(\mathrm{p}<0.01)$ found in this case, is accepted as a fact, which allows to say that melatonin induces tendency to hypercoagulability in rats. No less important information give the results obtained from the group of rats injected with luzindole. In this case, the blocking of melatonin receptors $\left(\mathrm{MT}_{1}\right.$ and $\left.\mathrm{MT}_{2}\right)$ induces a strong decrease of both the vWF antigen level (Fig. 4) (p<0.001), and vWF ac- 
Effects of Melatonin and Luzindole on plasma levels of tissue factor, tissue factor pathway inhibitor and Von Willebrand factor in rats

tivity (Fig. 5) $(\mathrm{p}<0.001)$. We believe that the significantly reduced values were primarily the result of the inability of endogenous melatonin to achieve its stimulating effects on the formation of vWF and its activation. From the application of luzindole followed by melatonin (the fourth group of rats) can be concluded that in essence it is not different from the just mentioned results, i.e. the third group (luzindole only). It is imperative to add that in this case, the blocking of melatonin receptors blocks the effects of both endogenous and exogenous melatonin, which may explain the significantly lower values of vWF:Ag (Fig. 4) $(\mathrm{p}<0.001)$ and vWF:Act (Fig. 5) $(\mathrm{p}<0.001)$ than those of the control group. It is seen that melatonin is an important regulator of the whole chain - from the biosynthesis of vWF to the formation of high activity vWF.

These results not only confirm the established in our previous studies effect of melatonin on hemostasis, namely - a tendency to hypercoagulability $(22,24,25)$, but also indicate that this hormone causes significant changes in TF, TFPI and vWF, which are the basis of this trend.

\section{CONCLUSION}

The results of our study allow us to summarize that the pineal hormone melatonin induces a pronounced tendency to hypercoagulability in rats by a significant increase of TF, decrease in plasma levels of free TFPI and free TFPI activity, as well as by an increase in vWF antigen and vWF activity. Luzindole self-administration and luzindole pretreatment show decisive involvement of $\mathrm{MT}_{1}$ and $\mathrm{MT}_{2}$ receptors for accomplishing the effects of the hormone.

\section{REFERENCES}

1. Kasthuri RS, Sam LG, Boles J, Mackman N. Tissue factor and tissue factor pathway inhibitor as key regulators of global hemostasis: measurement of their levels in coagulation assays. Semin Thromb Hemost. 2010;36:764-771.

2. Mackman N. Role of tissue factor in hemostasis, thrombosis, and vascular development. Arterioscler Thromb Vasc Biol. 2004;24(6):1015-1022.

3. Østerud B, Bjørklid E. Sources of tissue factor. Semin Thromb Hemost. 2006;32(1):11-23.

4. Schecter AD, Sprin B, Rossikhina M, Giesen PL, Bogdanov V, Fallon JT et al. Release of active tissue factor by human arterial smooth muscle cells. Circ Res. 2000;87(2):126-132.

5. Mumford AD, McVey JH. Tissue factor in the myocardium: evidence of roles in haemostasis and inflammation. Dis Markers. 2004;20(6):353-358.

6. Mann KG, Orfeo T, Butenas S, Undas A, BrummelZiedins K. Blood coagulation dynamics in haemostasis. Hamostaseologie. 2009;29(1):7-16.

7. Butenas S, Mann GK. Blood coagulation. Biochemistry 2002;67(1):3-12.

8. Ellery PE, Adams MJ. Tissue factor pathway inhibitor: then and now. Semin Thromb Hemost. 2014;40:881-886.

9. Wood JP, Ellery PE, Maroney SA, Mast AE. Biology of tissue factor pathway inhibitor. Blood 2014;123:2934-2943.

10. Bajaj MS, Kuppuswamy MN, Satio H, Spitzer SG, Bajaj SP. Cultured normal human hepatocytes do not synthesize lipoprotein-associated coagulation inhibitor: evidence that endothelium is the principal site of its synthesis. Proc Natl Acad Sci, USA 1990;87(22):8869-8873.

11. Mast AE, Acharya N, Malecha MJ, Hall CL, Dietzen DJ. Characterization of the association of tissue factor pathway inhibitor with human placenta. Arterioscler Thromb Vasc Biol. 2002;22(12):2099-2104.

12. Girard TJ, Warren LA, Novotny WF, Likert KM, Brown SG, Miletich JP et al. Functional significance of the Kunitz-type inhibitory domains of lipoprotein-associated coagulation inhibitor. Nature 1989;338(6215):518-520.

13. Petersen LC, Biørn SE, Olsen OH, Nordfang O, Norris F, Norris K. Inhibitory properties of separate recombinant Kunitz-type-protease-inhibitor domains from tissue-factor-pathway inhibitor. Eur J Biochem. 1996;235(1-2):310-316.

14. Baugh RJ, Broze Gr Jr, Krishnaswamy S. Regulation of extrinsic pathway factor Xa formation by tissue factor pathway inhibitor. J Biol Chem. 1998;273(8):4378-4386.

15. Crawley JT, Lane DA. The haemostatic role of tissue factor pathway inhibitor. Arterioscler Thromb Vasc Biol. 2008;28(2):233-242.

16. Reininger AJ. Function of von Willebrand factor in haemostasis and thrombosis. Haemophilia. 2008;14 Suppl 5:11-26. 
17. Szanto T, Joutsi-Korhonen L, Deckmyn H, Lassila R. New insights into von Willebrand disease and platelet function. Semin Thromb Hemost. 2012;38:55-63.

18. Vlot AJ, Koppelman SJ, Bouma BN, Sixma JJ. Factor VIII and von Willebrand factor. Thromb Haemost. 1998;79(3):456-465.

19. Mayadas TN, Wagner DD. von Willebrand factor biosynthesis and processing. Ann N Y Acad Sci. 1991;614:153-166.

20. McGrath RT, McRae E, Smith OP, O'Donnel JS. Platelet von Willebrand factor-structure, function and biological importance. $\mathrm{Br} J$ Haematol. 2010; 148(6):834-843.

21. Mackman N. Role of tissue factor in hemostasis and thrombosis. Blood Cells Mol Dis. 2006;36(2):104-107.

22. Pashalieva I, Decheva L, Stancheva E, Nyagolov Y, Negrev N. Melatonin and luzindole - induced effects on integral blood coagulation parameters in rats. Comptes rendus de L'Academie bulgare des Sciences 2014;67:1269-1274.

23. Vischer UM. von Willebrand factor, endothelial dysfunction, and cardiovascular disease. J Thromb Haemost. 2006;4:1186-1193.

24. Pashalieva I, Stancheva E, Decheva L, Nyagolov Y, Negrev N. Experimental date about effect of melatonin on the count and functional activity of thrombocytes. Comptes rendus de L'Academie bulgare des Sciences 2012;65:855-860.

25. Nyagolov Y, Stancheva E, Decheva L, Pashalieva I, Negrev N. Melatonin and luzindole effects on the activity of plasma clotting factors V, XI, XII and XIII in rat. Comptes Rendus de L'Academie bulgare des Sciences 2012;65:1151-1156. 